\title{
Design-build of photovoltaic panel data logger pressure
}

\author{
Maryantho Masarrang a, ${ }^{\text {; }}$ Sari Dewi ${ }^{\text {a, }}$; Aidynal Mustari ${ }^{\text {a, }}$; Yusnaini Arifin ${ }^{\text {a, }}{ }^{\text {, }}$; Rizana Fauzi ${ }^{\text {a, }}$ \\ ${ }^{a}$ Universitas Tadulako, Alamat, Jl. Soekarno Hatta KM. 09 Palu Sulawesi Tengah 90411, Indonesia \\ 1antho46.masarrang@gmail.com; ${ }^{2}$ aidynalmustari@gmail.com; ${ }^{3}$ sari_dewich@yahoo.com; ${ }^{4}$ yusnaini.arifin@gmail.com \\ 5 rfauzi86@gmail.com \\ * Corresponding author
}

Article history: Received December 01, 2020; Revised June 30, 2021; Accepted June 30, 2021; Available online August 07, 2021

\begin{abstract}
The scarcity of fossil fuel sources and the growing energy demand has resulted in more intensively searching for alternative energy. One alternative energy source that is suitable for the equatorial region is solar energy. One of the technologies for utilizing solar energy that has begun to be widely used in Indonesia is the photovoltaic (PV) system. The output of PV is highly dependent on environmental conditions, especially the intensity of the sun and temperature. In addition to these two factors, shading (shadows) and soiling (dust) also affects the PV output. So, this must be observed at all times by monitoring the voltage and current as the PV output. This study aims to design a PV panel instrumentation structure based on a data logger. PV output data in the form of voltage and current and environmental conditions such as ambient temperature and solar intensity were recorded in real-time. The measurement results from the data logger will be compared with manual measurements. PV output data, output voltage and current, as well as sunlight intensity were compared with measurements using an avometer. Temperature data will be compared with thermocouple measurements. PV in this study will be connected to a $1 \mathrm{kOhm}$ load resistor. The results of the data logger and manual measurements indicated an insignificant difference. The manual measurement was conducted every hour, from $09.00-16.00$. The maximum differences for voltage, PV output current, pyranometer voltage, and ambient temperature are $0.89 \mathrm{~V}, 0.0007 \mathrm{~A}, 0.00014 \mathrm{~V}$, and $0.25 \mathrm{oC}$, respectively.
\end{abstract}

Keywords: Photovoltaic; Data Logger; Alternative Energy

\section{Introduction}

The growing demand for energy and the scarce supply of fossil fuels has resulted in more intensively exploring alternative energy. Among these alternative energy sources, solar energy is one of the most abundant, clean, and renewable energy sources available. One of the uses of solar energy is photovoltaic (PV). This PV system is a sustainable solution in solving the problem of energy scarcity. The performance of this PV is highly dependent on environmental conditions, location, and conditions of the PV [1]

In tropical areas, the use of PV is more potential than other renewable energy sources [2]. According to NASA, in Indonesia, the sun's intensity reaching the surface is $5.5 \mathrm{kWh} / \mathrm{m} 2$ per day. However, the intensity of the sun arriving at the PV surface is highly fluctuating [3]. In addition, panel temperature, shading, and dust can affect the performance of the PV system [4]. The annual energy loss caused by partial shading is about $10-20 \%$ [5]. PV power losses can reach up to $70 \%$ in some locations due to soiling [6].

The evolution of renewable energy today, especially photovoltaic (PV), leads to the increasing use of PV. This evolution is in the form of a price decrease, its impact on the environment, as well as an increase in lifespan and efficiency [7]. The use of PV in the residential sector is currently growing in order to reduce the impact of fossilbased energy. Currently, in Indonesia, PV has begun to develop, both on a large scale and household scale. In tropical areas, the use of PV is more potential than other renewable energy sources [2]. According to NASA, in Indonesia, the sun's intensity reaching the surface is $5.5 \mathrm{kWh} / \mathrm{m} 2$ per day. However, the intensity of the sun arriving at the PV surface is highly fluctuating [3]. In addition, panel temperature, shading, and dust can affect the performance of the PV system [4]. The annual energy loss caused by partial shading is about $10-20 \%$ [5]. PV power losses can reach up to $70 \%$ in some locations due to soiling [6].

PV performance depends on environmental conditions, and the increasing use of PV makes the use of monitoring systems important. However, most of these PV systems do not yet have a good monitoring and maintenance system. The PV monitoring system provides information about the energy produced, converted, temperature, and energy losses from the PV system. In addition, the monitoring system can also provide early detection of disturbances and evaluate climate change [8]. The designation or several parameters that will be monitored in the PV monitoring system can be determined in advance [9]. In a PV performance monitoring system, knowing the monitoring parameters is essential. From previous studies on PV monitoring systems, the most decisive 
electrical and meteorological parameters on PV performance are solar intensity, PV and ambient temperature, voltage, and current output from PV. In contrast, other parameters depend on the configuration. Generally, photovoltaic (PV) system configurations are classified into stand-alone and grid-connected PV systems. The PV system can supply both DC and AC loads, even though the output of the PV is DC. PV systems can also be linked to energy storage systems and other energy sources.

The PV monitoring system consists of several sensors that provide information to the signal conditioning unit. This unit consists of a microcontroller that sends its output to a Personal Computer (PC) in real-time using a particular protocol. Some of the usually used sensors are current sensors, voltage sensors, solar radiation sensors, temperature sensors, anemometer sensors (wind speed), and humidity sensors. Generally, the PV monitoring system consists of 3 stages. First, the stage of reading data by sensors, second, entering the data processing stage and temporary data storage in the data logger, and third, the stage of data storage. Either on the cloud server or local storage and data access by the user.

Many PV data loggers have been developed recently [10]-[13]. Commercial data loggers already offer webbased functions. However, commercial PV data loggers also have drawbacks such as using a lot of energy, requiring a lot of space for storage, and usually cannot be added or expanded if other functions are desired [9]. In addition to commercial data loggers, there are many low-cost data logger developments where this can be created according to the purpose and parameters needed.

In the study [14], the designed data logger only monitors the electrical output data from Photovoltaic and only uses an SD card as storage. Meanwhile, in this proposed study, it has been developed to measure environmental data, in this case, the temperature and intensity of the sun. Although the error from the proposed study is still larger than in the study [14], the data is directly saved to the storage from the PC so that there are no limitations in storage. In addition, the data can be directly presented in excel form. Furthermore, in the study [15], a PV data logger has been developed using a microcontroller with SD card storage. In this study, in addition to PV electrical data, the data logger has also been able to measure environmental data in the form of temperature and solar intensity. The highest errors resulting from temperature and intensity measurements were $2.978 \%$ and $3.038 \%$, respectively. In this research, in addition to using PC storage, the errors generated for temperature and solar intensity are better, which are 0.0795 and $2.41 \%$.

\section{Method}

\section{A. System Design}

The data logger system used consists of a sensor as a reader of the output value of the PV (electrical quantity) and a sensor that reads the state of the environment. The environmental conditions to be monitored are radiation intensity and ambient temperature. The radiation intensity will be used by a pyranometer which will be connected to the microcontroller directly through an amplifier circuit. Sensor readings are carried out with an analog to digital converter (ADC) device that is already integrated into the minimum microcontroller system.

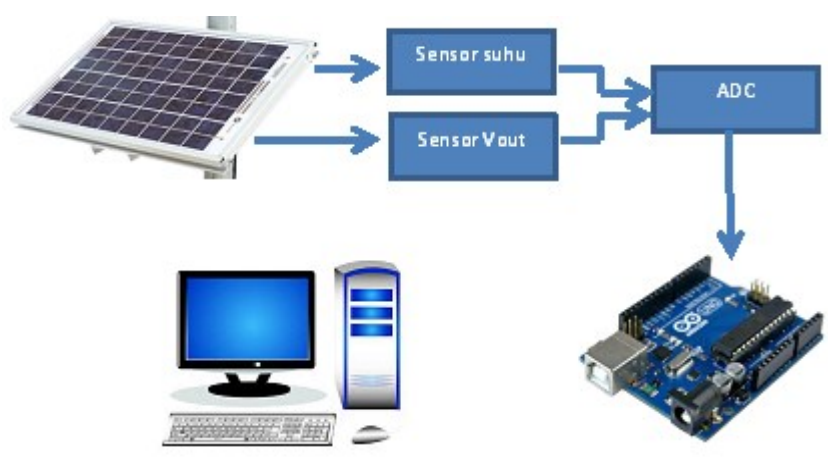

Figure 2. Design of data logger-based PV output logging system

In Figure 2, it can be seen that the first data processing is carried out by a sensor that reads the output value of the PV in the form of temperature, electric current, and voltage. The output from the sensor is forwarded to the analog-digital converter (ADC) contained in the Arduino module to be converted from analog data to digital data. This data is then processed by the microcontroller and forwarded using serial communication to a PC which will then be stored in the software in the operating system (OS). In this case, the software used is based on a database stored on the PC. The data stored is in the form of an excel file to be processed into the only values data or in the graphical form.

Besides the current and voltage values, this tool also uses a light intensity sensor, which is a pyranometer to detect and read how much light intensity is exposed to the photovoltaic. The value read by the pyranometer is then forwarded to the ADC pin on the Arduino module. This will then serve to convert the analog signal input from the 
sensor into a digital signal. The microcontroller contained in the Arduino, in this case, is the Atemega 328 microcontroller. This microcontroller has an Analog pin that can function as an Analog to Digital Converter (ADC). This pin can function as an ADC circuit, and it's just that with this analog pin, the tool does not require an additional circuit such as an ADC circuit. The series of data logger-based PV output recording devices can be seen in Figure 3. This circuit is connected to a load in the form of a $1 \mathrm{kOhm}$ resistor.

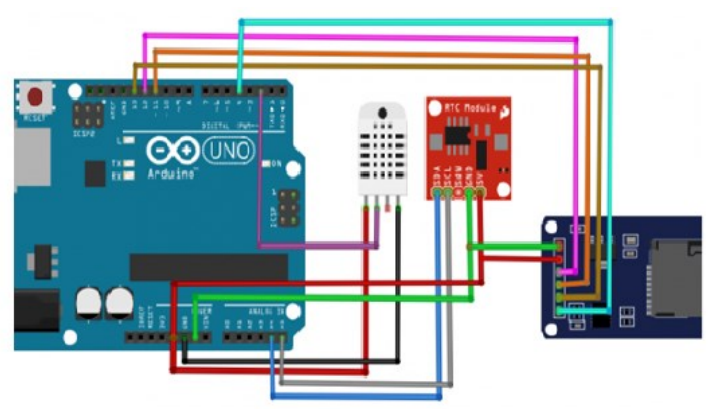

Figure 3. A series of data logger-based PV output recording tools

In measuring light intensity, this research used a pyranometer brand Kip \& Zonen, with a sensitivity of $13.11 \mathrm{x}$ 10-6 V/W/m2. The measurement output from the pyranometer is still in the form of voltage. To get it in the form of intensity, the measured voltage is divided by the sensitivity of the pyranometer. The conversion from voltage to intensity can be seen in equation (1).

\section{Intensity $=$ rated voltage $(\mathrm{V}) / 13,11 * 10^{-6} \mathrm{~W} / \mathrm{m}^{2}$}

Data logger measurements are carried out in real-time per 20 seconds. The hourly measurement will be validated by manual measurement using a conventional avometer. Measurements from the data logger will be averaged every hour, then compared with manual measurements. This applies to electrical output data in the form of PV output voltage and current and environmental data in the form of temperature and intensity. This measurement was carried out from $08.00-16.00$.

\section{B. Research Flow}

The research was carried out by observing the literature and references obtained and then conducting experiments on the developed design concept. The research flow and flowchart of the tool's work process can be seen in Figures 4 and Figures 5. Similar to the measurement of PV electrical output by a data logger, measurements of environmental conditions, which is the temperature, and radiation intensity, are carried out every 20 seconds.

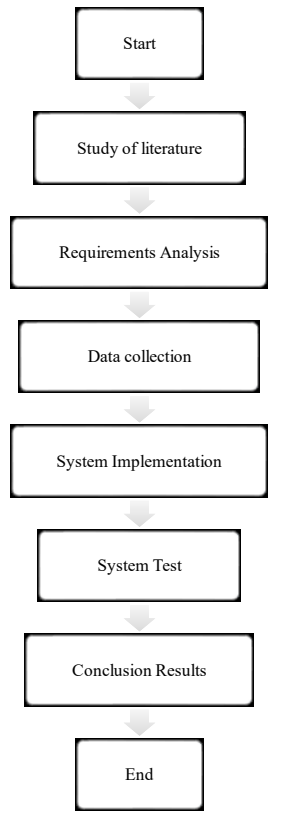

Figure 4. Research flow

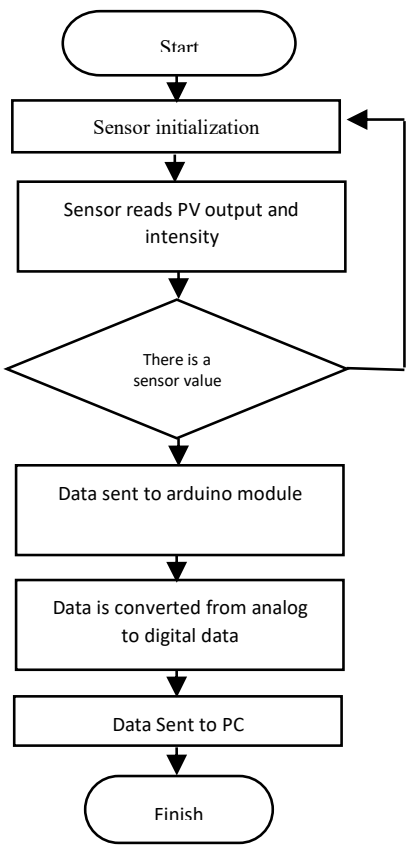

Figure 5. Flowchart of tool work 


\section{Results and Discussion}

From the data logger that has been designed and built, the data has been successfully collected. The data recorded by the data logger is compared with manual measurements using an Avometer, which are the voltage, current, temperature, and intensity data. At the same time, the temperature data is compared with the thermocouple.

The data logger records every 20 seconds, but validation with manual measurements is carried out once an hour, starting from $09.00-16.00$. The measurement results indicate voltage and current are accurate, but there are still insignificant differences. The difference in PV output, voltage, and current can be seen in Table 2. The table shows that the maximum difference in voltage and current is 0.89 volts and $0.0007 \mathrm{~A}$, respectively.

Table 2. Comparison of PV electric output measurements using a data logger and avometer

\begin{tabular}{|c|c|c|c|c|c|c|c|}
\hline \multirow{2}{*}{ No } & \multirow{2}{*}{$\begin{array}{c}\text { Collect } \\
\text { time }\end{array}$} & \multicolumn{2}{|c|}{$\begin{array}{c}\text { Open Circuit } \\
\text { Voltage PV (Volt) }\end{array}$} & $\begin{array}{c}\text { Short Circuit } \\
\text { Current PV } \\
\text { (Ampere) }\end{array}$ & $\begin{array}{c}\text { Difference between } \\
\text { data logger and } \\
\text { avometer } \\
\text { measurements }\end{array}$ \\
\cline { 3 - 8 } & & $\begin{array}{c}\text { Data } \\
\text { log }\end{array}$ & Avometer & $\begin{array}{c}\text { Data } \\
\text { log }\end{array}$ & Avometer & Voltage & Current \\
\hline 1. & 09.00 & 11.20 & 11,69 & 0.011 & 0.011 & 0.49 & 0.0002 \\
\hline 2. & 10.00 & 12.06 & 12,63 & 0.012 & 0.012 & 0.57 & 0.0001 \\
\hline 3. & 11.00 & 13.08 & 13,45 & 0.013 & 0.013 & 0.37 & 0.0001 \\
\hline 4. & 12.00 & 14.65 & 15,45 & 0.014 & 0.014 & 0.80 & 0.0002 \\
\hline 5. & 13.00 & 16.77 & 17,66 & 0.017 & 0.017 & 0.89 & 0.0002 \\
\hline 6. & 14.00 & 18.27 & 18,67 & 0.019 & 0.018 & 0.40 & 0.0005 \\
\hline 7. & 15.00 & 17.97 & 18,78 & 0.019 & 0.018 & 0.81 & 0.0007 \\
\hline 8. & 16.00 & 15.88 & 15,89 & 0.016 & 0.016 & 0.01 & 0.0001 \\
\hline
\end{tabular}

For environmental data in the form of ambient temperature and solar intensity, it can be seen in Table 3. From table 3 it can be seen that the maximum difference from intensity measurements using a data logger and avometer is $0.00014 \mathrm{~V}$. When converted to intensity units, it is equivalent to $0.000014 / 13.11 \times 10-6 \mathrm{~W} / \mathrm{m} 2$ or equal to $10.61 \mathrm{~W} / \mathrm{m} 2$. Then, for the ambient temperature, the biggest difference is $0.25 \mathrm{oC}$.

Table 3. Comparison of environmental data measurements using a data logger and avometer

\begin{tabular}{|c|c|c|c|c|c|c|c|}
\hline \multirow{2}{*}{ No } & \multirow{2}{*}{$\begin{array}{c}\text { Collect } \\
\text { time }\end{array}$} & \multicolumn{2}{|c|}{$\begin{array}{c}\text { Open Circuit } \\
\text { Voltage PV (Volt) }\end{array}$} & \multicolumn{2}{|c|}{$\begin{array}{c}\text { Ambient temperature } \\
\left({ }^{\mathbf{0}} \mathbf{C}\right)\end{array}$} & $\begin{array}{c}\text { Difference between data } \\
\text { logger and avometer } \\
\text { measurements }\end{array}$ \\
\cline { 3 - 8 } & & $\begin{array}{c}\text { Data } \\
\text { log }\end{array}$ & Avometer & Data log & Termokopel & $\begin{array}{c}\text { Sun } \\
\text { intensity }\end{array}$ & $\begin{array}{c}\text { Ambient } \\
\text { temperature }\end{array}$ \\
\hline 1. & 09.00 & 0.0054 & 0.0053 & 28.07 & 28.08 & 0.00010 & 0.01 \\
\hline 2. & 10.00 & 0.0059 & 0.0058 & 29.21 & 29.31 & 0.00014 & 0.10 \\
\hline 3. & 11.00 & 0.0121 & 0.0120 & 30.69 & 30.71 & 0.00012 & 0.02 \\
\hline 4. & 12.00 & 0.0133 & 0.0132 & 31.77 & 31.52 & 0.00007 & 0.25 \\
\hline 5. & 13.00 & 0.0141 & 0.0140 & 33.15 & 33.15 & 0.00011 & 0.00 \\
\hline 6. & 14.00 & 0.0082 & 0.0081 & 32.11 & 32.23 & 0.00007 & 0.12 \\
\hline 7. & 15.00 & 0.0079 & 0.0080 & 31.53 & 31.55 & 0.00011 & 0.02 \\
\hline 8. & 16.00 & 0.0074 & 0.0075 & 30.98 & 31.12 & 0.00008 & 0.14 \\
\hline
\end{tabular}

The graph of the comparison of measurements between the data logger and manual measurements can be seen in Figure 6 (a) for voltage, Figure 6 (b) for current, Figure 6 (c) for intensity, and Figure 6 (d) for solar intensity.

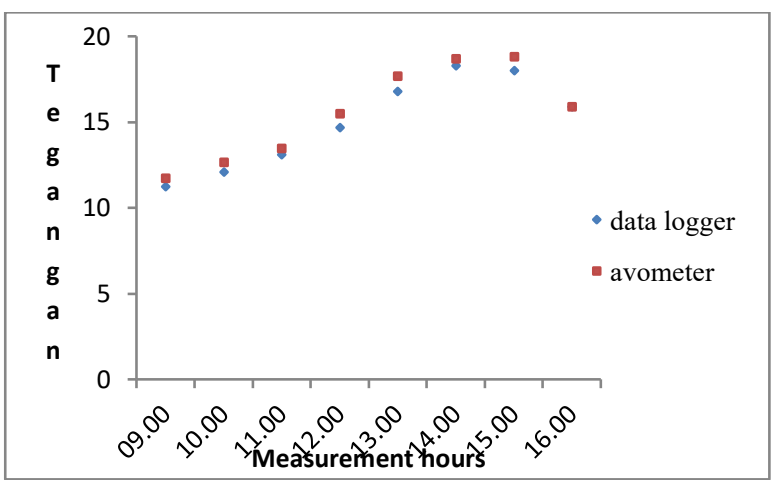

(a)

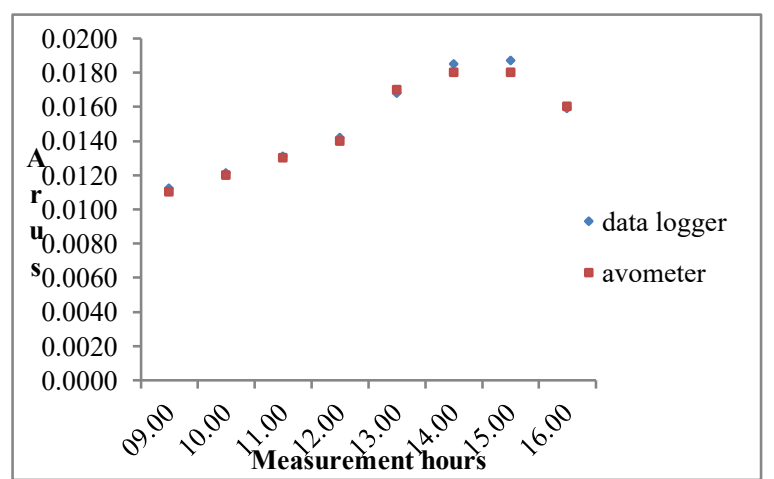

(b) 


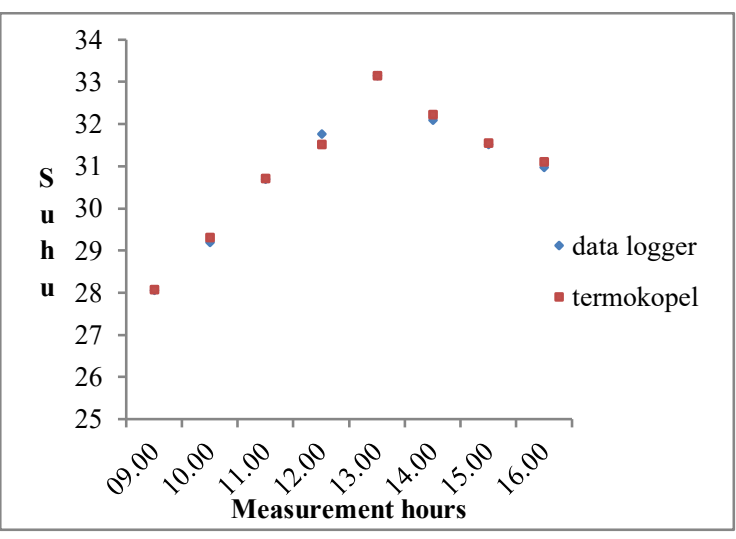

(c)

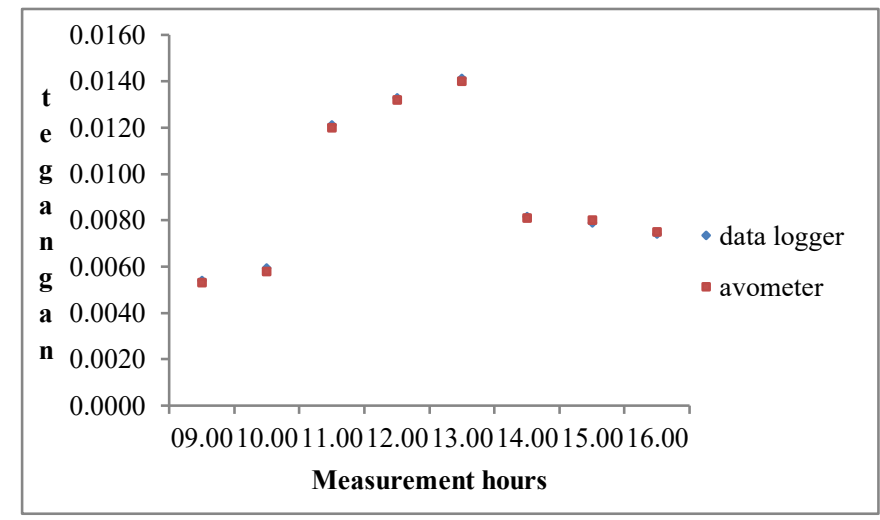

(d)

Figure 6. Comparison of data logger measurements with manual measurements (a) PV output voltage; (b) PV output current; (c) ambient temperature; and (d) pyranometer voltage.

\section{Conclusion}

From the comparison results between measurements made using a data logger and manual measurements, both for PV output voltage, PV output current, ambient temperature, and solar intensity, it can be concluded that the design of this tool has been successful. This can be seen from the maximum difference between measurements with data loggers with manual measuring instruments (avometer for PV output voltage, PV output current, pyranometer output voltage, and thermocouple for ambient temperature) is already small. The maximum difference for the measurement of PV output voltage, PV output current, pyranometer output voltage (solar intensity), and ambient temperature are $0.89 \mathrm{~V}, 0.0007 \mathrm{~A}, 0.00014 \mathrm{~V}$, and $0.25 \mathrm{oC}$, respectively.

\section{Acknowledgement}

The author thanks the Faculty of Engineering, Tadulako University, which has provided financial assistance to conduct this research. The author also conveys to Fatur and Amran for their assistance in data collection.

\section{References}

[1] Sofia Fanourakis, Kevin Wang, Patrick McCarthy, and Lihong (Heidi) Jiao, "Low-Cost Data Acquisition Systems for Photovoltaic System Monitoring and Usage Statistics," J. Energy Power Eng., vol. 11, no. 11, pp. 719-728, 2017, doi: 10.17265/1934-8975/2017.11.005.

[2] G. K. Singh, "Solar power generation by PV (photovoltaic) technology: A review," Energy, vol. 53, pp. 1-13, 2013, doi: 10.1016/j.energy.2013.02.057.

[3] Syafaruddin, D. Galla, and W. A. F. A. Ajami, "Design of boat powered photovoltaic systems," Appl. Sol. Energy (English Transl. Geliotekhnika), vol. 50, no. 4, pp. 207-214, 2014, doi: 10.3103/S0003701X1404015X.

[4] S. Fanourakis, K. Wang, P. McCarthy, and L. Jiao, "Low-cost data acquisition systems for photovoltaic system monitoring and usage statistics," IOP Conf. Ser. Earth Environ. Sci., vol. 93, no. 1, 2017, doi: 10.1088/1755$1315 / 93 / 1 / 012048$.

[5] A. J. Hanson, C. A. Deline, S. M. MacAlpine, J. T. Stauth, and C. R. Sullivan, "Partial-shading assessment of photovoltaic installations via module-level monitoring," IEEE J. Photovoltaics, vol. 4, no. 6, pp. 1618-1624, 2014, doi: 10.1109/JPHOTOV.2014.2351623.

[6] A. Woyte, M. Richter, D. Moser, S. Mau, N. Reich, and U. Jahn, "Monitoring of Photovoltaic Systems: Good Practices and Systematic Analysis," J. Chem. Inf. Model., vol. 53, no. 9, pp. 1689-1699, 2013.

[7] V. Beránek et al., "New Monitoring System for Photovoltaic Power Plants' Management," 2018, doi: 10.3390/en11102495.

[8] S. R. Madeti and S. N. Singh, "Monitoring system for photovoltaic plants: A review," Renew. Sustain. Energy Rev., vol. 67, pp. 1180-1207, 2017, doi: 10.1016/j.rser.2016.09.088.

[9] M. M. Rahman, J. Selvaraj, N. A. Rahim, and M. Hasanuzzaman, "Global modern monitoring systems for PV based power generation: A review," Renew. Sustain. Energy Rev., no. July, pp. 1-17, 2017, doi: 10.1016/j.rser.2017.10.111.

[10] B. Soumia, M. K. Nallapaneni, and T. Ali, "Data acquisition system: On the solar photovoltaic module and weather parameters monitoring," Procedia Comput. Sci., vol. 132, pp. 873-879, 2018, doi: 10.1016/j.procs.2018.05.099.

[11] A. Mahjoubi, R. F. Mechlouch, and A. Ben Brahim, "A low cost wireless data acquisition system for a remote photovoltaic (PV) water pumping system," Energies, vol. 4, no. 1, pp. 68-89, 2011, doi: 10.3390/en4010068. 
[12] A. M. Krishna, K. P. Rao, M. B. Prakash, and N. Ramchander, "Data Acquisition System for Performance Monitoring of Solar Photovoltaic ( PV ) Power Generation,” IIJERT nternational J. Eng. Res. Technol., vol. 1, no. 7, pp. 1-6, 2012, doi: 10.13140/RG.2.2.15797.47844.

[13] H. Belmili, S. M. Ait Cheikh, M. Haddadi, and C. Larbes, "Design and development of a data acquisition system for photovoltaic modules characterization," Renew. Energy, vol. 35, no. 7, pp. 1484-1492, 2010, doi: 10.1016/j.renene.2010.01.007.

[14] N. N. Mahzan, A. M. Omar, L. Rimon, S. Z. M. Noor, and M. Z. Rosselan, "Design and development of an arduino based data logger for photovoltaic monitoring system," Int. J. Simul. Syst. Sci. Technol., vol. 17, no. 41, pp. 15.1-15.5, 2017, doi: 10.5013/IJSSST.a.17.41.15.

[15] A. Lopez-Vargas, M. Fuentes, M. V. Garcia, and F. J. Munoz-Rodriguez, "Low-Cost Datalogger Intended for Remote Monitoring of Solar Photovoltaic Standalone Systems Based on ArduinoTM,” IEEE Sens. J., vol. 19, no. 11, pp. 4308-4320, 2019, doi: 10.1109/JSEN.2019.2898667. 